\title{
Developing Nursing Care Standards among Adult Patients with Uncontrolled Essential Hypertension
}

\author{
Wallaa F. Muhammad, Hala M. Ghanem \& Ahmed M. Aly Obiedallah. \\ Teacher at Dirout nursing school Assiut, Egypt. \\ Assistant Prof. of Medical Surgical Nursing (Adult Nursing), Faculty of Nursing, Assiut University, Egypt. \\ Lecturer of Internal Medicine, Faculty of Medicine, Assiut University, Egypt.
}

\begin{abstract}
Aims of this study: to developing nursing care standards among adult patients with uncontrolled essential hypertension through the following1- identify the needs of hypertensive patients2- develop nursing care standards for adult patients with uncontrolled essential hypertension according to their needs 3-assess nurses' knowledge about uncontrolled essential hypertension. Subjects and methods: Descriptive exploratory study was utilized .The study was carried out at internal medicine department at Assiut University Hospital. The study sample was composed of (53) nurses and (60) adult patients with uncontrolled essential hypertension. Tools: four tools were utilized for data collection Questionnaire sheet for nurse's knowledge regarding nursing care for patients with uncontrolled essential hypertension, Basic nurses competencies opinionnaire tool, Nurses practice observation checklist, patient's needs assessment tool. Results: showed that; More than three quarters of nurses (75.5\%) had poor knowledge about nursing care for patients with uncontrolled essential hypertension. Conclusion: Formulation of standards is the first step toward evaluating nursing care delivery. Recommendation: In-service training program for nurses is important in internal medicine department. Application of the nursing care standards for patients with uncontrolled essential hypertension.
\end{abstract}

\section{Keywords: Nursing Care Standards \& Uncontrolled Essential Hypertension.}

\section{Introduction}

Hypertension (HTN) is a progressive cardiovascular syndrome arising from Complex and interrelated etiologies. Early markers of the syndrome are often present before blood pressure elevation is sustained; therefore hypertension cannot be classified solely by discrete blood pressure thresholds. Progression is strongly associated with functional and structural cardiac and vascular abnormalities that damage the heart, kidneys, brain, vasculature and other organs and lead to premature morbidity and death (Roger et al., 2012).

According to report of American Heart Association, (2012). HTN is a major risk factor for heart disease, stroke, and kidney disease. It affects nearly one-third of American adults aged 18 or older $(67$ million people).HTN is uncontrolled in more than half of adults with the condition, or 36 million people. Only $61 \%$ of adults with uncontrolled HTN are aware they have HTN, and just under half (45\%) of the uncontrolled both know they have HTN and are being treated with medications to lower their blood pressure.

Uncontrolled essential hypertension can be attributed to poor adherence to antihypertensive drugs, excessive salt intake, physician inertia,

inappropriate or inadequate medication, drug-induced hypertension, obstructive sleep apnea, primary aldosteronism, and chronic kidney disease represent the most common secondary causes of Uncontrolled hypertension ;Several drugs can induce or exacerbate pre-existing hypertension, with non-steroidal antiinflammatory (NSAIDs) drugs being the most common due to their wide use. Obstructive sleep apnea and primary aldosteronism are frequently encountered in patients with Uncontrolled Hypertension and require expert management. (Calhoun et al., 2008).

Hypertension is often referred to as the silent killer, since patients can remain asymptomatic for years before organ damage produces symptoms, sometimes catastrophically. Elevated BP is strongly associated with increased risk of coronary artery disease events(myocardial infarction, revascularization, and angina pectoris)and stroke, as well as congestive heart failure, peripheral vascular disease, aortic aneurysms, and deterioration of vision in diabetes, and renal failure this risk increases when blood pressure is uncontrolled (Lloyd-Jones et al., 2009). Effective management and control of HTN can reduce the risks of heart attack, stroke, and heart failure. Although lifestyle changes such as eating a healthy, low-sodium diet, getting more exercise, and quitting smoking may result in small decreases in blood pressure, people with HTN generally also require one or more medications to lower their blood pressure. Clinical trials have shown that blood pressure medications have the potential to reduce the 
incidence of stroke by $35 \%-40 \%$, heart attacks by $20 \%-25 \%$, and heart failure by $50 \%$ (Chobanian et al., 2003).

Nursing care standard for hypertensive patients focuses on lowering and controlling the blood pressure without adverse effects and without undue cost; To achieve these goals, the nurse must support and teach the patient to adhere to the treatment regimen by implementing necessary lifestyle changes, taking medications as prescribed, and scheduling regular follow-up appointments with the health care provider to monitor progress or identify and treat any complications of disease or therapy (Zipes \& Bonow, 2005).

Significance of the study

Uncontrolled essential hypertension is a common health problem in Egypt. It has a high prevalence, whereas its rates of awareness and treatment are low. In $60 \%$ of patients, hypertension is complicated by the presence of other cardiovascular risk factors, this adds to increased cardiovascular morbidity and mortality. This study will be the first study in this geographical location which will help nurses to develop nursing care standard for patient with uncontrolled essential hypertension.

\section{Aims of the study}

The aims of this study are: to assess nurses' knowledge about uncontrolled essential hypertension, to identify the needs of hypertensive patients and to develop standards of nursing care among adult patients with uncontrolled essential hypertension.

\section{Research questions}

What are nurses knowledge regarding uncontrolled essential hypertension?

What are nursing care standards among adult patients with uncontrolled essential hypertension?

\section{Subjects \& methods}

\section{Research Design}

Descriptive expletory design was utilized to achieve the aim of this study.

Setting; The study was conducted in the Internal Medicine Department at Assiut University Hospital.

Subjects: Sample of all available nurses (53) working in internal medicine department who are participate in the study. In addition 60 patients who are new medically diagnosed with uncontrolled hypertension were selected according to the following criteria

Exclusion criteria: Patient with known to have secondary hypertension, Patient who has chronic kidney disease and Patient who have endocrine disease.
Tools; Four tools were used in this study and developed by the researcher to collect the necessary data for this study.

Tool I: Nurse's knowledge Questionnaire sheet It was developed by the researcher based on current national and international literature to assess their knowledge regarding uncontrolled essential hypertension in addition to some selected biosocial characteristics data for nurses it consisted of three parts.

Part I: Socio-demographic data This part comprised nurse's age, level of education, sex, and years of experience, marital status and qualifications it included 6 items (questions from 1 to 6 ).

Part II: Nurses' knowledge about uncontrolled essential hypertension This part included (19) items (questions from 7 to 25) as regarding nurses' knowledge about uncontrolled essential hypertension as definition of essential hypertension, definition of resistance hypertension definition of white coat hypertension causes of uncontrolled essential hypertension, symptoms of uncontrolled essential hypertension, diagnosis of essential hypertension, Investigation for patient with essential hypertension and complication of uncontrolled essential hypertension .

Part III: Nursing management and guidelines This part included (8) items (questions from 26 to 33) as regarding nursing management (Immediate nursing intervention after admission, routine nursing intervention for patient with uncontrolled essential hypertension, guidelines that given to patients before discharge).

Scoring system The total number of questions was (27). Each complete answer was get score of (2) and incomplete answer was get score of (1) but unknown answer was get score of (0). The total scores were $(100 \%)$. Those who obtained less than $50 \%$ were considered having poor level. While those who obtained from $50-70 \%$ were considered having fair level While those who obtained more than $70 \%$ were considered having good level.

Tool II: Nurses practice observation checklist sheet This tool included nurses practice related to procedures required for patient with uncontrolled essential hypertension it was covered the following procedures; vital signs (blood pressure, pulse, respiration and temperature), Electrocardiography (ECG), peripheral venous catheter, blood glucose, fluid intake, output, body mass index , and nurse's general precaution for infection control (Hand washing, Wear gloves) and nurse's general precaution of Infection control.

Scoring system The total score of observation checklist sheet was (199) items, each item in checklist was scored as follow: two degree for each 
step that done correct (correctly, in time and with the required frequency) and one degree for each step done incorrect (incorrectly, not in time and without the required frequency) and zero for step that not done. Inapplicable means that the nurses were not able to apply the principles of the standard due to shortage in supplies and equipment, not due to shortage or negligence from the nurses.

Tool III: Basic nurse's opinionnaire sheet: it was developed by the researcher based on current national and international literature in order to elicit opinions of nurses as regard: the basic nursing care for patient with uncontrolled essential hypertension.

The scoring system of the nurses' opinionnaire was as follow:

Competencies of care

score

Agree

Disagree

0

Tool IV: Patients' assessment sheet: this tool was developed by the researcher based on the current national and international literature to identify patient needs with uncontrolled essential hypertension. It is consists of three parts:

Part I: Socio-demographic data This part comprised patient's age, sex, level of education, occupation marital status, Residence and smoking It included (8) items (questions from 1 to 8 )

Part II: Medical data (medical diagnosis and health history (clinical presentation); It includes (5) items(questions from 9 to 13) as regard patient's family history of hypertension, family history of obesity, family history of cardiovascular disease, and Onset of symptoms of hypertension and Increase of symptoms with Stress or increase salt intake or Increase activities .

Part III: health assessment This part It includes (15) items (questions from 14 to 28) as regard patient's Skin condition, , Eye condition, Ears condition, Nose condition, Mouth and Oral cavity condition, Neck condition, cardiovascular system, Gastrointestinal tract system G.I.T, Lower limbs, Neurological problems, Symptoms of hypertension, History of development of numbness of fingers, Measurements (height, Weight and BMI), vital signs and Laboratory investigation .

\section{Methods}

- Content validity was established by panel of (5) expertises from medical and surgical nursed staff

- An official letter was issued from the Dean of the Faculty of Nursing to the Head of the internal medicine department at Assuit university hospitals soliciting the necessary approval to conduct the present research. After explain the aim of the study and the program to them to obtain their cooperation.
- A pilot study carried out in February 2014 to test the feasibility and practicability of the study tools on $10 \%$ of sample (5nurses and 6 patient ).

- Data were collected from Internal Medicine Department at Assuit university hospitals from 23 February until 23 May 2014.

- Each nurse and patient was informed with the purpose of the study participation is voluntary.

\section{Statistical Design}

Data was collected \&analyzed by computer programmed spss (ver. 16). Using necessary statistical manipulation as; number, percentage, mean\& standard deviation to determine significant for variables-value was considered to be significant if less than 0.05 , high significant if less than 0.01 , or insignificant if more than 0.05 .

\section{Limitations of the study}

Observation sheet took a long time because observation include immediate, routine and before discharge of patients. Most nurses not understand what the meaning of standards and not understand opinionnaire sheet so explained took long time. 


\section{Results}

Table (1): Distribution of the characteristics of the studied nurses (No:53).

\begin{tabular}{|c|c|c|}
\hline Characteristics & No. $(n=53)$ & $\%$ \\
\hline \multicolumn{3}{|l|}{ Gender } \\
\hline Male & 20 & 37.7 \\
\hline Female & 33 & 62.3 \\
\hline \multicolumn{3}{|l|}{ Age: (years) } \\
\hline$<20$ & 1 & 1.9 \\
\hline $20-30$ & 30 & 56.6 \\
\hline$\geq 30$ & 22 & 41.5 \\
\hline Mean \pm SD & $31.5 \pm 10.1$ & Mean \pm SD \\
\hline \multicolumn{3}{|l|}{ Marital status } \\
\hline Single & 21 & 39.6 \\
\hline Married & 31 & 58.5 \\
\hline Divorced & 1 & 1.9 \\
\hline \multicolumn{3}{|l|}{ Level of education } \\
\hline Diploma of nursing & 50 & 94.3 \\
\hline baccalaureate of nursing & 3 & 5.7 \\
\hline \multicolumn{3}{|l|}{ Years of experience } \\
\hline$>5$ & 21 & 39.6 \\
\hline $5-10$ & 10 & 18.9 \\
\hline$>10$ & 22 & 41.5 \\
\hline Mean \pm SD & $7.9 \pm 4.2$ & \\
\hline \multicolumn{3}{|l|}{ Attending training courses } \\
\hline Yes & 32 & 60.4 \\
\hline No & 21 & 39.6 \\
\hline \multicolumn{3}{|l|}{ Number of training courses } \\
\hline One & 27 & 84.4 \\
\hline More than one & 5 & 15.6 \\
\hline
\end{tabular}

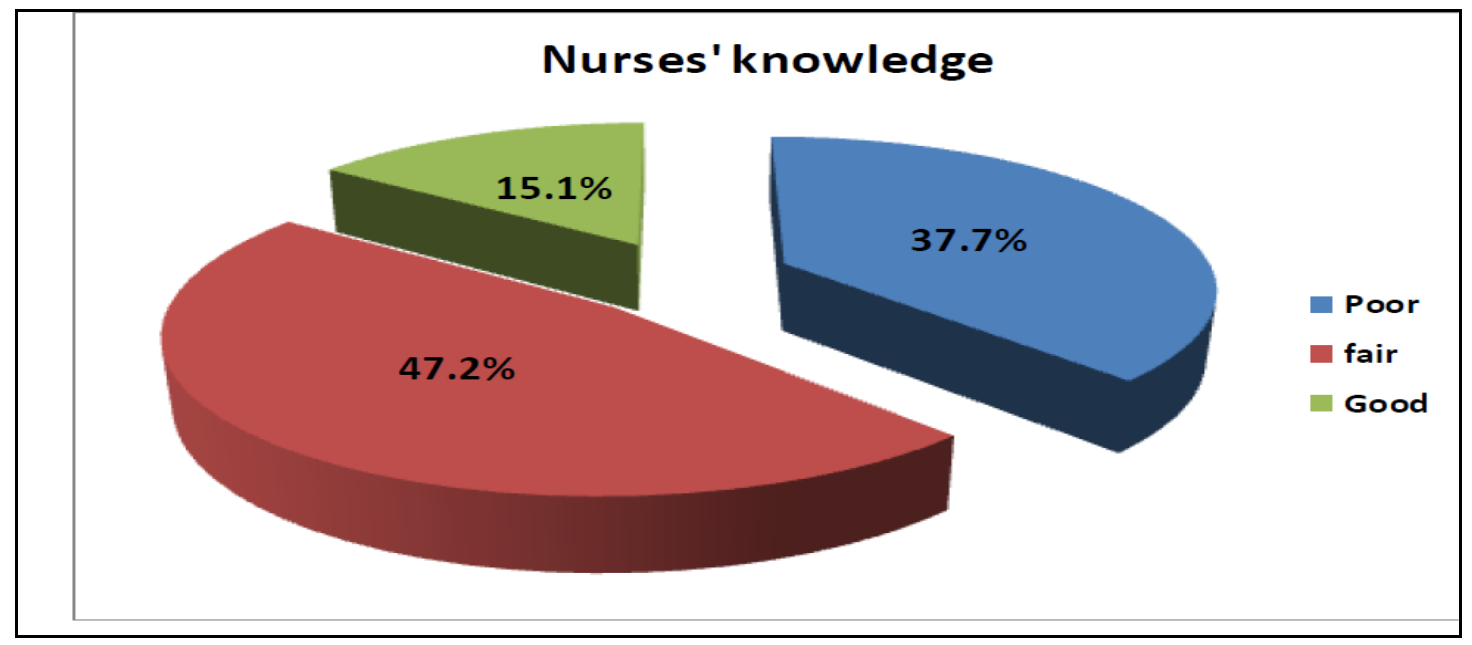

Fig (1): nurses' knowledge about uncontrolled essential hypertension No (53) 


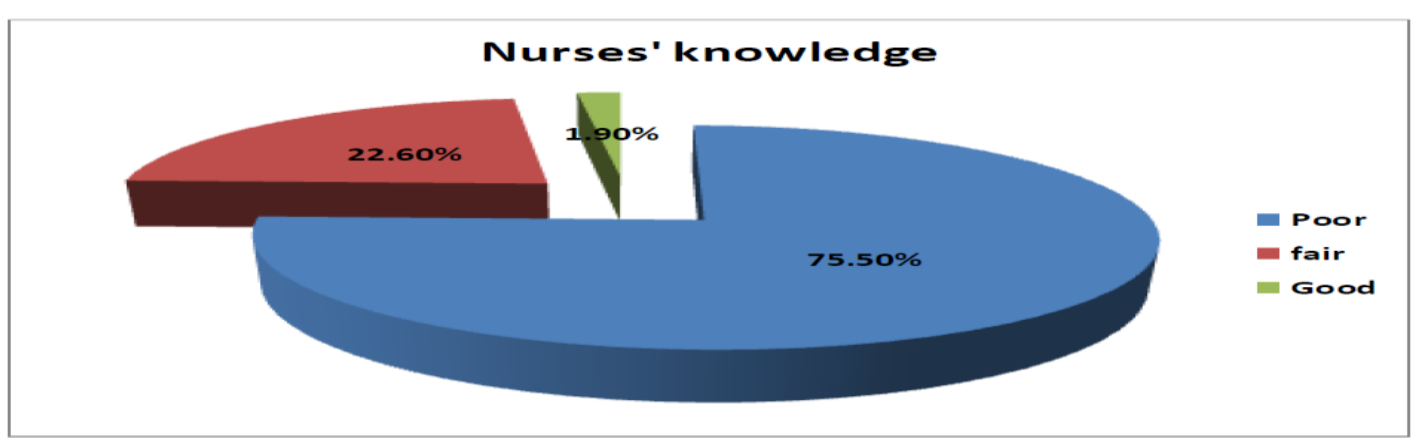

Fig (2): Nurses' Knowledge about nursing intervention for patient with uncontrolled essential hypertension

Nurses' practice

- As regarding Measuring blood pressure procedure this study shows that: all steps of measuring blood pressure had not done.

- The level of nurse's practice as regarding Count Pulse rate procedure the study shows that: all steps of counting pulse had not done.

- The level of nurse's practice as regarding measuring respiration procedure the present study shows that: all steps of monitoring respiratory rate, depth and character not done.

- As regarding measuring body mass index procedure: the present study shows that all of steps for measuring weight and height are not applicable.

Table (2): Distribution the level of nurse's practice as regarding electrocardiogram (ECG) procedure.

\begin{tabular}{|c|c|c|c|c|c|c|c|c|}
\hline \multirow{3}{*}{ ECG procedure } & \multicolumn{4}{|c|}{ Done } & \multirow{2}{*}{\multicolumn{2}{|c|}{ ND }} & \multirow{2}{*}{\multicolumn{2}{|c|}{ NA }} \\
\hline & \multicolumn{2}{|c|}{$\mathbf{C}$} & \multicolumn{2}{|c|}{ I } & & & & \\
\hline & No. & $\%$ & No. & $\%$ & No. & $\%$ & No. & $\%$ \\
\hline 1- Hand washing & 0 & 0.0 & 0 & 0.0 & 53 & 100 & 0 & 0.0 \\
\hline 2- explain the purpose of ECG and procedure to the patient & 8 & 15.1 & 8 & 15.1 & 37 & 69.8 & 0 & 0.0 \\
\hline $\begin{array}{l}\text { 3-Ask The patient to lie in supine position and be } \\
\text { relaxed as possible. }\end{array}$ & 53 & 100 & 0 & 0.0 & 0 & 0.0 & 0 & 0.0 \\
\hline \multicolumn{9}{|l|}{ 4-Apply chest leads and limb leads as follows } \\
\hline RA-right arm & 53 & 100 & 0 & 0.0 & 0 & 0.0 & 0 & 0.0 \\
\hline LA-left arm & 53 & 100 & 0 & 0.0 & 0 & 0.0 & 0 & 0.0 \\
\hline RL-right leg & 53 & 100 & 0 & 0.0 & 0 & 0.0 & 0 & 0.0 \\
\hline LL-left leg & 53 & 100 & 0 & 0.0 & 0 & 0.0 & 0 & 0.0 \\
\hline V1-4th intercostals space at right sternal border & 35 & 66.0 & 18 & 33.9 & 0 & 0.0 & 0 & 0.0 \\
\hline V2-4th intercostals space at left sternal border & 35 & 66.0 & 18 & 33.9 & 0 & 0.0 & 0 & 0.0 \\
\hline V3-Directly between V2 and V4 & 35 & 66.0 & 18 & 33.9 & 0 & 0.0 & 0 & 0.0 \\
\hline V4-5th intercostals space at midclavicular line & 35 & 66.0 & 18 & 33.9 & 0 & 0.0 & 0 & 0.0 \\
\hline V5-Level with V4 at the left anterior axillary line & 35 & 66.0 & 18 & 33.9 & 0 & 0.0 & 0 & 0.0 \\
\hline 5-Instruct patient to remain still & 53 & 100 & 0 & 0.0 & 0 & 0.0 & 0 & 0.0 \\
\hline 6-Press to acquire/record the ECG & 53 & 100 & 0 & 0.0 & 0 & 0.0 & 0 & 0.0 \\
\hline $\begin{array}{l}\text { 7-Observe the ECG quality and decide if another } \\
\text { recording is necessary }\end{array}$ & 53 & 100 & 0 & 0.0 & 0 & 0.0 & 0 & 0.0 \\
\hline 8-Remove leads and cleans pt skin. & 8 & 15.1 & 45 & 84.9 & 0 & 0.0 & 0 & 0.0 \\
\hline 9-return the patient to a comfortable position-thanks patient & 0 & 0.0 & 28 & 52.8 & 25 & 47.2 & 0 & 0.0 \\
\hline 10-write pt full name-Date -Time of recording on ECG & 53 & 100 & 0 & 0.0 & 0 & 0.0 & 0 & 0.0 \\
\hline 11-Clean the leads with an approved solution & 0 & 0.0 & 0 & 0.0 & 53 & 100 & 0 & 0.0 \\
\hline 12-show ECG record to physician as soon as possible. & 53 & 100 & 0 & 0.0 & 0 & 0.0 & 0 & 0.0 \\
\hline 14-Hand washing & 0 & 0.0 & 0 & 0.0 & 53 & 100 & 0 & 0.0 \\
\hline
\end{tabular}


Table (3): Distribution the level of nurse's practice as regarding measuring blood glucose procedure.

\begin{tabular}{|c|c|c|c|c|c|c|c|c|}
\hline \multirow{3}{*}{ measuring blood glucose } & \multicolumn{4}{|c|}{ Done } & \multirow{2}{*}{\multicolumn{2}{|c|}{ ND }} & \multirow{2}{*}{\multicolumn{2}{|c|}{ NA }} \\
\hline & \multicolumn{2}{|c|}{$\mathbf{C}$} & \multicolumn{2}{|c|}{$\mathbf{I}$} & & & & \\
\hline & No. & $\%$ & No. & $\%$ & No. & $\%$ & No. & $\%$ \\
\hline $\begin{array}{l}\text { 1-Collect together all the equipment including: test } \\
\text { meter, test strips, finger pricking device/lancet, clean } \\
\text { gauze and the patient's records. }\end{array}$ & 53 & 100 & 0 & 0.0 & 0 & 0.0 & 0 & 0.0 \\
\hline $\begin{array}{l}\text { 2-Explain the procedure to the patient and gain verbal } \\
\text { consent. }\end{array}$ & 8 & 15.1 & 35 & 66.0 & 10 & 18.9 & 0 & 0.0 \\
\hline 3- Wash hands. & 0 & 0.0 & 8 & 15.1 & 45 & 84.9 & 0 & 0.0 \\
\hline 4- Apply gloves. & 0 & 0.0 & 4 & 7.5 & 49 & 92.5 & 0 & 0.0 \\
\hline $\begin{array}{l}\text { 5- Ask the patient to wash and dry her or his hands. If not, } \\
\text { wash finger with soap and water and allow drying. }\end{array}$ & 0 & 0.0 & 0 & 0.0 & 53 & 100 & 0 & 0.0 \\
\hline $\begin{array}{l}\text { 6-Ensure that the patient is sitting or lying } \\
\text { comfortably before the procedure. }\end{array}$ & 0 & 0.0 & 28 & 52.8 & 25 & 47.2 & 0 & 0.0 \\
\hline 7-Ensure the code strip matches the meter code. & 53 & 100 & 0 & 0.0 & 0 & 0.0 & 0 & 0.0 \\
\hline $\begin{array}{l}\text { 8-Use lancet device to pierce the skin at the side of } \\
\text { the finger and encourage bleeding by use of gravity. } \\
\text { Avoid squeezing finger as this may affect the result }\end{array}$ & 28 & 52.8 & 25 & 47.2 & 0 & 0.0 & 0 & 0.0 \\
\hline 9- Wipe first drop of blood with sterile gauze & 0 & 0.0 & 3 & 5.7 & 50 & 94.3 & 0 & 0.0 \\
\hline $\begin{array}{l}\text { 10- Encourage bleeding to obtain a drop large enough } \\
\text { to cover the test strip. }\end{array}$ & 53 & 100 & 0 & 0.0 & 0 & 0.0 & 0 & 0.0 \\
\hline 11-Apply this drop of blood to the test strip.- & 53 & 100 & 0 & 0.0 & 0 & 0.0 & 0 & 0.0 \\
\hline 12- Apply gauze to prevent further bleeding. & 0 & 0.0 & 3 & 5.7 & 50 & 94.3 & 0 & 0.0 \\
\hline 13-Promptly dispose of lancet into sharps bin.- & 28 & 52.8 & 11 & 20.8 & 14 & 26.4 & 0 & 0.0 \\
\hline 14-Record the result clearly in nursing notes. & 53 & 100 & 0 & 0.0 & 0 & 0.0 & 0 & 0.0 \\
\hline 15-Remove and safely discard gloves. & 0 & 0.0 & 4 & 7.5 & 49 & 92.5 & 0 & 0.0 \\
\hline 16-Safely dispose of any waste. & 20 & 37.7 & 19 & 35.8 & 14 & 26.4 & 0 & 0.0 \\
\hline
\end{tabular}

Table (4): Distribution the level of nurse's practice as regarding universal precaution for infection control procedure.

\begin{tabular}{|c|c|c|c|c|c|c|c|c|}
\hline \multirow{3}{*}{ Infection control precaution } & \multicolumn{4}{|c|}{ Done } & \multirow{2}{*}{\multicolumn{2}{|c|}{ ND }} & \multirow{2}{*}{\multicolumn{2}{|c|}{ NA }} \\
\hline & \multicolumn{2}{|c|}{$\mathrm{C}$} & \multicolumn{2}{|c|}{ I } & & & & \\
\hline & No. & $\%$ & No. & $\%$ & No. & $\%$ & No. & $\%$ \\
\hline $\begin{array}{l}\text { 1-Follow hospital procedures for routine care to } \\
\text { prevent nosocomial infection. }\end{array}$ & 0 & 0.0 & 38 & 71.7 & 15 & 28.3 & 0 & 0.0 \\
\hline $\begin{array}{l}\text { 2-Cleaning and disinfection of environmental } \\
\text { surfaces beds, bedrails and bedside equipment with } \\
\text { disinfected solution daily. }\end{array}$ & 0 & 0.0 & 0 & 00 & 53 & 100 & 0 & 0.0 \\
\hline $\begin{array}{l}\text { 3- Cleaning and disinfection touched surfaces when } \\
\text { contaminated with blood, body fluids and secretions. }\end{array}$ & 0 & 0.0 & 34 & 64.2 & 19 & 35.8 & 0 & 0.0 \\
\hline $\begin{array}{l}\text { 4-Ensure that air-conditioners are cleaned regularly } \\
\text { or in accordance to the policy of preventive } \\
\text { maintenance for health of the hospital. }\end{array}$ & 0 & 0.0 & 0 & 0.0 & 53 & 100 & 0 & 0.0 \\
\hline 5-Use disposable equipment whenever possible. & 18 & 34.0 & 31 & 58.5 & 4 & 7.5 & 0 & 0.0 \\
\hline 6-maintain hygienic care every day. & 0 & 0.0 & 0 & 0.0 & 53 & 100 & 0 & 0.0 \\
\hline $\begin{array}{l}\text { 7-provide meticulous skin care to prevent enter of } \\
\text { pathogens. }\end{array}$ & 0 & 0.0 & 0 & 0.0 & 53 & 100 & 0 & 0.0 \\
\hline $\begin{array}{l}\text { 8-encourage frequent deep breathing and cough to } \\
\text { prevent respiratory infections. }\end{array}$ & 0 & 0.0 & 0 & 0.0 & 53 & 100 & 0 & 0.0 \\
\hline
\end{tabular}




\begin{tabular}{|c|c|c|c|c|c|c|c|c|}
\hline \multirow{3}{*}{ Infection control precaution } & \multicolumn{4}{|c|}{ Done } & \multirow{2}{*}{\multicolumn{2}{|c|}{ ND }} & \multirow{2}{*}{\multicolumn{2}{|c|}{$\mathbf{N A}$}} \\
\hline & \multicolumn{2}{|c|}{$\mathbf{C}$} & \multicolumn{2}{|c|}{$\mathbf{I}$} & & & & \\
\hline & No. & $\%$ & No. & $\%$ & No. & $\%$ & No. & $\%$ \\
\hline Never recap needles using both hands. & 0 & 0.0 & 38 & 71.7 & 15 & 28.3 & 0 & 0.0 \\
\hline 1-Use either one hand. & 0 & 0.0 & 35 & 66.0 & 18 & 34.0 & 0 & 0.0 \\
\hline $\begin{array}{l}\text { 2- Use mechanical device designed for holding the } \\
\text { needle sheath. }\end{array}$ & 0 & 0.0 & 34 & 64.2 & 19 & 35.8 & 0 & 0.0 \\
\hline $\begin{array}{l}\text { 3-Place used disposable syringes, needles, scalpels and } \\
\text { other sharp items in puncture-resistant sharp containers. }\end{array}$ & 0 & 0.0 & 34 & 64.2 & 19 & 35.8 & 0 & 0.0 \\
\hline
\end{tabular}

Table (5): Distribution of nurses' opinions for nursing care standard for uncontrolled essential hypertension.

\begin{tabular}{|c|c|c|c|c|}
\hline \multirow{2}{*}{ Items } & \multicolumn{2}{|c|}{ Agree } & \multicolumn{2}{|c|}{ Disagree } \\
\hline & No. & $\%$ & No. & $\%$ \\
\hline $\begin{array}{l}\text { I- Ensures that the internal medicine department are ready } \\
\text { to receive hypertensive patient }\end{array}$ & 53 & 100 & 0 & 0.0 \\
\hline 1. Prepare the internal medicine with the necessary equipment. & 50 & 94.3 & 3 & 5.7 \\
\hline $\begin{array}{l}\text { 2. Prepare the car table with basic instrument according to } \\
\text { patient condition. }\end{array}$ & 51 & 96.2 & 2 & 3.8 \\
\hline 3. Prepare patient room. & 52 & 98.1 & 1 & 1.9 \\
\hline \multicolumn{5}{|c|}{$\begin{array}{l}\text { II- Ensure that the internal medicine department environment are safe to receive patient with } \\
\text { uncontrolled essential hypertension }\end{array}$} \\
\hline 1. Identifying your patient. & 52 & 98.1 & 1 & 1.9 \\
\hline 2. Preventing patient falls by. & 50 & 94.3 & 3 & 5.7 \\
\hline 3. Reporting accidents and errors. & 51 & 96.2 & 2 & 3.8 \\
\hline $\begin{array}{l}\text { 4. Maintaining safe environment in administration of } \\
\text { medication. }\end{array}$ & 51 & 96.2 & 2 & 3.8 \\
\hline $\begin{array}{l}\text { III- Ensure that continuous monitoring and recording are } \\
\text { followed for hypertensive patients }\end{array}$ & 53 & 100 & 0 & 0.0 \\
\hline 1. Immediate nursing care. & 51 & 96.2 & 2 & 3.8 \\
\hline 2-Routine nursing care. & 51 & 96.2 & 2 & 3.8 \\
\hline 3-Health education for patients before discharge & 51 & 96.2 & 2 & 3.8 \\
\hline \multicolumn{5}{|l|}{$\begin{array}{l}\text { III- Ensures that all infection control measures are properly } \\
\text { followed in all procedures }\end{array}$} \\
\hline 1. Principle of aseptic technique in all procedure. & 52 & 98.1 & 1 & 1.9 \\
\hline 2. Identify and supervise methods of disinfecting the following. & 52 & 98.1 & 1 & 1.9 \\
\hline $\begin{array}{l}\text { V- Ensures that all health team are properly for patient } \\
\text { intervention. }\end{array}$ & 50 & 94.3 & 3 & 5.7 \\
\hline $\begin{array}{l}\text { VII- Ensures that all staff (health team) follows ethics and } \\
\text { patients right in internal medicine department. }\end{array}$ & 52 & 98.1 & 1 & 1.9 \\
\hline
\end{tabular}


Part V: Distribution of patient's characteristics:

Table (6): characteristics of the studied patients (No:60).

\begin{tabular}{|c|c|c|}
\hline Characteristics of the studied patients & No. $(n=60)$ & $\%$ \\
\hline \multicolumn{3}{|l|}{ Gender } \\
\hline Male & 17 & 28.3 \\
\hline Female & 43 & 71.7 \\
\hline \multicolumn{3}{|l|}{ Age: (years) } \\
\hline $31-40$ & 30 & 50.0 \\
\hline $41-50$ & 26 & 43.3 \\
\hline $51-65$ & 4 & 6.7 \\
\hline Mean \pm SD & $49.7 \pm 7.2$ & Mean \pm SD \\
\hline \multicolumn{3}{|l|}{ Marital status } \\
\hline Single & 1 & 1.7 \\
\hline Married & 43 & 71.7 \\
\hline Divorced & 16 & 26.7 \\
\hline \multicolumn{3}{|l|}{ Level of education } \\
\hline High education & 3 & 5.0 \\
\hline Secondary education & 10 & 16.7 \\
\hline Read and write & 6 & 10.0 \\
\hline Illiterate & 41 & 68.3 \\
\hline \multicolumn{3}{|l|}{ Residence } \\
\hline Urban & 21 & 35.0 \\
\hline Rural & 39 & 65.0 \\
\hline \multicolumn{3}{|l|}{ Occupational status } \\
\hline Office work & 7 & 11.7 \\
\hline Machinery work & 3 & 5.0 \\
\hline Manual worker & 10 & 16.7 \\
\hline Professional & 3 & 5.0 \\
\hline Not working & 37 & 61.7 \\
\hline \multicolumn{3}{|l|}{ Smoking } \\
\hline Smokers & 17 & 28.3 \\
\hline Non smokers & 43 & 71.7 \\
\hline
\end{tabular}

Table (7): Distribution of medical data for studied patients'(No: 60).

\begin{tabular}{|c|c|c|c|c|c|c|}
\hline \multirow{2}{*}{ Items } & \multicolumn{4}{|c|}{ Yes } & \multicolumn{2}{|c|}{ No } \\
\hline & \multicolumn{2}{|c|}{ No. } & \multicolumn{2}{|c|}{$\%$} & No. & $\%$ \\
\hline Family history of hypertension & \multicolumn{2}{|c|}{32} & \multicolumn{2}{|c|}{53.3} & 28 & 46.7 \\
\hline Family history of obesity & \multicolumn{2}{|c|}{27} & \multicolumn{2}{|c|}{45.0} & 33 & 55.0 \\
\hline Family history of cardiovascular disease & \multicolumn{2}{|c|}{26} & \multicolumn{2}{|c|}{43.3} & 34 & 56.7 \\
\hline \multicolumn{7}{|l|}{ Increase of symptoms with } \\
\hline Stress & \multicolumn{2}{|c|}{60} & \multicolumn{2}{|c|}{100} & 0 & 0.0 \\
\hline increase salt intake & \multicolumn{2}{|c|}{53} & \multicolumn{2}{|c|}{88.3} & 7 & 11.7 \\
\hline Increase activities & \multicolumn{2}{|c|}{11} & \multicolumn{2}{|c|}{18.3} & 49 & 81.7 \\
\hline \multirow{3}{*}{ Onset of symptoms of hypertension } & \multicolumn{2}{|c|}{$<5$ year } & \multicolumn{2}{|c|}{ 5-10 year } & \multicolumn{2}{|c|}{$<10$ year } \\
\hline & No. & $\%$ & No. & $\%$ & No. & $\%$ \\
\hline & 26 & 43.3 & 21 & 35.0 & 13 & 21.7 \\
\hline
\end{tabular}


Table (8): frequency \&percentage distribution of the patients under study regarding 'health Assessment.

\begin{tabular}{|c|c|c|c|c|}
\hline \multirow{2}{*}{ Items } & \multicolumn{2}{|c|}{ Yes } & \multicolumn{2}{|c|}{ No } \\
\hline & No. & $\%$ & No. & $\%$ \\
\hline \multicolumn{5}{|l|}{ 1- Skin condition } \\
\hline Pallor. & 41 & 68.3 & 19 & 31.7 \\
\hline Cyanosis. & 26 & 43.3 & 34 & 56.7 \\
\hline Edema. & 6 & 10 & 54 & 90.0 \\
\hline Cold. & 13 & 21.7 & 47 & 78.3 \\
\hline Dry. & 26 & 43.3 & 34 & 56.7 \\
\hline Skin lesion. & 0 & 0.0 & 60 & 100 \\
\hline \multicolumn{5}{|l|}{ 2-Eye condition } \\
\hline Retinal bleeding. & 0 & 0.0 & 60 & 100 \\
\hline Retinal lesion. & 0 & 0.0 & 60 & 100 \\
\hline Excess tearing. & 0 & 0.0 & 60 & 100 \\
\hline \multicolumn{5}{|l|}{ 3- Ears condition: } \\
\hline Tinnitus & 58 & 96.7 & 2 & 3.3 \\
\hline \multicolumn{5}{|l|}{ 4- Nose condition } \\
\hline Epistaxsis. & 17 & 28.3 & 43 & 71.7 \\
\hline \multicolumn{5}{|l|}{ 5- Mouth and Oral cavity condition: } \\
\hline Tongue - Dry. & 13 & 21.7 & 47 & 78.3 \\
\hline Tongue-Moist. & 26 & 43.3 & 34 & 56.7 \\
\hline \multicolumn{5}{|l|}{ 6-Neck condition } \\
\hline Raised jugular veins. & 19 & 31.7 & 41 & 68.3 \\
\hline \multicolumn{5}{|l|}{ 7- Cardio vascular system } \\
\hline Chest pain. & 14 & 23.3 & 46 & 76.7 \\
\hline $\begin{array}{l}\text { Heart failure. } \\
\text { Right sided } \\
\text {-Dyspepsia: anorexia, nausea, vomiting } \\
\text {-LL swelling and abdominal distension } \\
\text {-dizziness, giddiness, and syncope } \\
\text {-oliguria } \\
\text {-Congested neck veins } \\
\text { - Enlarged tender liver } \\
\text { - LL edema and ascites } \\
\text { Left sided heart failure } \\
\text { Cough } \\
\text { Hemoptysis } \\
\text { dizziness, giddiness, and syncope } \\
\text { BP: low systolic BP } \\
\text { Coldness and peripheral cyanosis. }\end{array}$ & 0 & 0.0 & 60 & 100 \\
\hline Myocardial infarction. & 0 & 0.0 & 60 & 100 \\
\hline Irregular heartbeat. & 17 & 28.3 & 43 & 71.7 \\
\hline \multicolumn{5}{|l|}{ 8- Gastrointestinal tract system G.I.T } \\
\hline Nausea. & 45 & 75.0 & 15 & 25.0 \\
\hline Vomiting. & 11 & 18.3 & 49 & 81.7 \\
\hline 9-Lower limbs: & 6 & 10.0 & 54 & 90.0 \\
\hline Edema. & 12 & 20.0 & 48 & 80.0 \\
\hline Pain. & 42 & 70.0 & 18 & 30.0 \\
\hline D.V.T. & 0 & 0.0 & 60 & 100 \\
\hline
\end{tabular}




\begin{tabular}{|c|c|c|c|c|}
\hline \multirow{2}{*}{ Items } & \multicolumn{2}{|c|}{ Yes } & \multicolumn{2}{|c|}{ No } \\
\hline & No. & $\%$ & No. & $\%$ \\
\hline \multicolumn{5}{|l|}{ 10-Neurological problems } \\
\hline Numbness. & 0 & 0.0 & 60 & 100 \\
\hline Neuropathy. & 0 & 0.0 & 60 & 100 \\
\hline Parathesia. & 0 & 0.0 & 60 & 100 \\
\hline Dizziness. & 45 & 75.0 & 15 & 25.0 \\
\hline \multicolumn{5}{|l|}{ 11-Symptoms of hypertension } \\
\hline Headache. & 59 & 98.3 & 1 & 1.7 \\
\hline Fatigue. & 60 & 100 & 0 & 0.0 \\
\hline Vision problems. & 18 & 30.0 & 42 & 70.0 \\
\hline Difficulty breathing. & 31 & 51.7 & 29 & 48.3 \\
\hline Irregular heartbeat. & 16 & 26.7 & 44 & 73.3 \\
\hline 12-History of development of numbness of fingers: & 1 & 1.7 & 59 & 98.3 \\
\hline \multicolumn{5}{|l|}{ 13-Measurements } \\
\hline Height & 0 & 0.0 & 60 & 100 \\
\hline Weight & 0 & 0.0 & 60 & 100 \\
\hline BMI & 0 & 0.0 & 60 & 100 \\
\hline 14- Vital signs & 60 & 100 & 0 & 0.0 \\
\hline \multicolumn{5}{|l|}{ 15-laboratory investigation } \\
\hline Hemoglobin & 18 & 30.0 & 42 & 70.0 \\
\hline $\mathrm{RBCs}$ & 39 & 65.0 & 21 & 35.0 \\
\hline ECG & 55 & 91.7 & 5 & 8.3 \\
\hline Urinalysis & 53 & 88.3 & 7 & 11.7 \\
\hline Fasting blood glucose & 44 & 73.3 & 16 & 26.7 \\
\hline Hematocrit & 12 & 20.0 & 48 & 80.0 \\
\hline Serum sodium & 57 & 95.0 & 3 & 5.0 \\
\hline Potassium & 59 & 98.3 & 1 & 1.7 \\
\hline Creatinine & 57 & 95.0 & 3 & 5.0 \\
\hline Calcium & 55 & 91.7 & 5 & 8.3 \\
\hline Lipid profile & 32 & 53.3 & 28 & 46.7 \\
\hline
\end{tabular}

Table (1): showed that more than half of nurses $(62.3 \%)$ are female. (56.6\%) of nurses their age ranged from (20-30) years. (58.5\%) of them were married. Most of them (94.3\%) had diploma of nursing. (41.5\%) of nurses had $(<10)$ years of experience. As regard to previously of attended training programs, it was found that (84.4) were not attending training program about hypertension. As regard to other training course as infection control.

Figure (1): reflected that nearly half of nurses (47.2\%) had fair level of knowledge as regarding uncontrolled essential hypertension. Minority of nurses (15.1\%) had good level of knowledge as regarding uncontrolled essential hypertension.
Figure (2): shows that; More than three quarters of nurses 75.5 had poor knowledge about nursing care for patients with uncontrolled essential hypertension.

Table (2): shows that majority of nurses had done correctly electrocardiogram (ECG) making.

Table (3): shows that majority of nurses had done correct (measuring blood glucose) standard practice.

Table (4): shows that the majority of nurses had not done incorrectly (Infection control precaution).

Table (5): this table cleared that vast majority of nurses agreed the basic nursing competencies for patient with uncontrolled essential hypertension.

Table (6): this table shows that two thirds of patients $(71.7 \%)$ are female. $(50.0 \%)$ of patients their age ranged from (31-40) years. (71.7\%) of them were married. $(68.3 \%)$ of them are illiterate. $(65.0 \%)$ of 
them are lived in rural areas. $(61.7 \%)$ of them are not working. $(71.7 \%)$ of them are non-smokers.

Table (7): this table shows that more than half of patient $(53.3 \%)$ had a family history of hypertension. More than half of patients had no (family history of obesity and family history of cardiovascular disease) with percent $(55.0 \%, 56.7 \%)$.Vast majority of patients had increase of symptoms with stress and increase in salt intake with percent $(100 \%, 88.3 \%)$.

Table (8): this table shows that the vast majority of patient suffering from Headache and all of patient had Fatigue and all of patient take vital signs regularity by the doctors the majority of patient mad laboratory investigation

\section{Discussion}

Based on the results of the present study, more than half of nurses their age ranged from 20- 30 years, female, married, and have diploma of nursing. Theminority of them has in-service training courses related to infection control but the majority of them have no in-service training courses related to hypertension. Ahmed, (2011); in the same line with the current study findings conducted a study in kidney dialysis unit atAssiut University Hospital entitled "Effect of designed nursing protocol on nurse's knowledge and practice regarding haemodialysis patients" the majority of the nurses were married, female, their age ranged from 20-30 years, have a diploma qualification, years of experiences in haemodialysis units ranged from 20 30 and have in-service training courses related to infection control precautions.

Marquis \& Huston, (2009); stated that, education and training are two components of staff development that occur after an employees' indoctrination (which refers to planned, guided adjustment of employee to the organization and work environment). The staffs' knowledge level and capabilities are a major factor in determining the number of staff required to carry out unit goals. The better trained and more competent the staff, the fewer staff required, which in turn saves the organization money and rise reproductively.

Furthermore, the result of this study revealed that nearly half of nurses had fair level of knowledge as regarding uncontrolled essential hypertension. These results are consistence with Abd El-Fatah, (2013), who conducts study on "Assessment of Quality of Life and Nurses' Knowledge for Hypertensive Elderly Patients at Sohag University Hospital" that reveals, the general level of nurses' knowledge regarding hypertension is relatively fair. These results may be attributed to the fact that they are not concerned with reading updated information.
On the other hand, this finding disagrees with Isioma, (2012) who studied the nurse's knowledge and attitude in the prevention and management of hypertension in primary health care centers in Delta state Nigeria and reported that, more than half of nurses had good knowledge about hypertension.

The present study showed that more than three quarters of nurses had poor knowledge score level about nursing intervention for patients with uncontrolled essential hypertension. This interpretation is in agreement with Samer, (2005) who stated that the nurses concern in their work on the routine nursing care. This result disagree with Dianne McMahon, (2011) stated that the nurse is responsible and accountable for the quality of nursing care given to patients. The single most important protective strategy for the nurse is to be a knowledgeable and safe practitioner of nursing and to meet the standards of care with all patients. Nurses are empowered by the society of care and the trust of the physician and the patient to ensure quality care.

Based on the present study, all of nurses had not done all steps of measuring blood pressure these result disagree with Rose, (2010) who stated that, vital signs is a fundamental component of nursing care. It include patient's pulse, respiration, blood pressure and body temperature that are essential in identifying clinical deterioration and that these parameters must be measured consistently and recorded accurately. These results disagree with Pickering, (2005) who stated that, the standards for blood pressure measurement, including conditions required before measurements are made, equipment specifications, and techniques for measuring blood pressure to obtain accurate and reliable readings. When the patient begins an antihypertensive treatment regimen, blood pressure assessments are needed to determine the effectiveness of medication therapy and to detect any changes in blood pressure that may indicate the need for modification in the treatment plan.

The present study showed that, all steps of counting pulse had not done. This study disagreed with Suzanne, (2008) who stated that, the nurse must also pay specific attention to the rate, rhythm, and character of the apical and peripheral pulses to detect effects of hypertension on the heart and blood vessels. A thorough assessment can yield valuable information about the extent to which the hypertension has affected the body and about any other personal, social, or financial factors related to the condition.

The present Study showed that all steps of measuring respiratory rate, depth and character not done. This could be due to respiratory monitoring not a routine care. This result in contrast with Mustafa, (2012) who stated, respiratory assessment is an important 
component of health assessment and is a valuable tool in patient management. However many nurses still regard these skills within the domain of the medical officer and a not legitimate nursing activity.. The present study showed that, the majority of nurses had done correctly ECG procedure. Electrocardiography is the most commonly used test for evaluating cardiac status. Also ECG is regarded as a routine procedure for cardiac patient so; nurses can practice frequently and be familiar with it.

Nurses also need to maintain and enhance ECG skills. Keller and Raines, (2005) published that a qualitative study of nurses which indicated that the skills necessary to recognize and treat arrhythmias could be categorized as basic, intermediate or advanced. Identification of specific arrhythmias including heart block, aberrant conduction, and tachyarrhythmia varied across training and experience levels within the test sample. The finding of the study disagreed with Funk et al., (2009) who found that, despite major advances in electrocardiographic (ECG) monitoring technology, monitoring practices are inconsistent and often inadequate. It is unclear whether this is partly due to knowledge deficits of nurses.

The present study showed that, the majority of nurses had done correct measuring blood glucose. This result agreed with Ibrahim, (2004) who stated that, measures the amount of glucose in the blood right at the time of sample collection; hyperglycemia may result from elevated catecholamine levels, which increases BP, and use of thiazide diuretics. Also, diabetes mellitus can be associated with hypertension. Therefore healthcare providers must not only identify and treat patients with hypertension but also make them aware of associated consequences of hypertension.

The present study showed that, all steps of assessment of body mass index (measuring weight and height) are not applicable. These results disagree with Douketis, (2005) who stated that, BMI and waist circumference should be used as one part of a more comprehensive assessment of health risk. BMI and waist circumference should be assessed as part of a routine physical examination.

Ibrahim, (2004) who stated that, excess body weight (body mass index of 27 or greater) is correlated closely with increased blood pressure. Excess fat in the upper parts of the body (abdominal), defined as waist circumference $\geq 85 \mathrm{~cm}$ in women or $\geq 98 \mathrm{~cm}$ in men, increases the risk of hypertension, dyslipidemia, diabetes and cardiovascular mortality. One kilogram decrease in body weight is accompanied by an average reduction of 1.6 and $1.3 \mathrm{mmHg}$ in systolic and diastolic blood pressure respectively, although the ideal is to maintain normally body weight.
As regard general Infection control precaution the majority of nurses had not done (general Infection control precaution). These results agree with Mohammed, (2011) who mentioned that, educational program focused on the application of standard precaution declined the prevalence of nosncomial blood and respiratory tract infection. As nurses were washing their hands only if contaminated with blood and before eating.

Moreover, the previous result contradicted with Marquis \& Huston, (2009) reported that each organization and profession must set standards and objectives to guide individuals and practitioners in performing safe and effective care. Also not only must standards exit, but leader and managers also must see that subordinates know and understand the standards and employee must be aware that their performance will be measured in terms of their ability to meet the established standards.

In addition, the nurses' practice regarding standard nursing care of hypertensive patients may also be influenced by other factors. These may the possible reasons for explaining this inadequate level of practice might be due to the limited working time in direct patient care, shortage of nursing staff, inadequate equipment, absence or ignorance of clear job description, and changes in hospital policy. These were not explored in this current study. Future research is needed to explore the relationships of these factors and nursing practice.

As regard to ensures that the internal medicine department environments are ready to receive the hypertensive patient the vast majority of nurses had agreed about all components of this competency. As for preparing the internal medicine department with the necessary equipments, prepare patient room and components of internal medicine department. This finding may be related to that some nurses had long years of experience. So they aware of the necessary equipment and preparation for hypertensive patient.

The present study revealed that: the vast majority of nurses had agreed for ensures that the internal medicine department environments are safe to receive hypertensive patients This basic competency include hospital acquired infection, preventing patient falls, reporting accidents and errors, maintaining safe environment in administration of medication, maintaining comfort.

This is in contrast with Fortunato, (2002) university of Virginia health system structures ensure that nurses are working and caring for patients in a safe practice environment. Many of the activities to assure a safe and secure environment of care for patients also support a safe environment for present staff. The link between safe, competent practice, high-quality 
patient outcomes and a healthy productive work environment is well-established in the healthcare.

The present study showed that, the vast majority of nurses agreed with continuous monitoring and recording for hypertensive patients. Which included immediate nursing care for patient with hypertension, routine nursing care for patient with hypertension and discharge advice. Mustafa, (2012) in the same line with the current study findings conducted a study in the trauma unit at Assiut University Hospital entitled" Developing standards of post-operative nursing interventions for lower limb amputated patients" who found that, the majority of nurses had agreed with continuous monitoring and recording for post operative amputated patients which included immediate post operative period, routine post operative period, avoid post operative complications, discharge advice.

The findings of the present study showed that, the vast majority of nurses had agreed as regarding ensure that all infection control measures are properly followed in all procedures. This can be due to attending in service training programs related to infection control measures. This competency included the following criteria, identify and supervise methods of disinfecting (walls, floor, chair, nursing room) and using universal precaution.

These findings in contrast with Magnum, (2001) who stated that, proper cleaning reduces the amount of exogenous microorganisms in environment, and helps to reduce air born contaminants that may travel on dust and settle on surfaces. In addition, cleaning should be performed on scheduled basis and should providesafe, visibly clean environment for patients to protect patient and staff.

In relation to ensure that health team is properly attired for patient care. All of nurses had agreed about this competency. In this context with College of Nurses of Ontario, (2009) stated that, personal protective equipment (PPE) is designed to protect the skin and the mucous membranes of the eyes, nose, and mouth of dental health-care personnel from exposure to blood or other potentially infectious material.

Based on the present study, the vast majority of nurses agreed as regarding all staff follow ethics and patients right in the internal medicine department. This result agreed with the Canadian Nurses Association's Code of Ethics for Registered Nurses. Code of Ethics is a statement of the ethical values of nurses and of nurses' commitments to persons with health-care needs and persons receiving care. It is intended for nurses in all contexts and domains of nursing practice and at all levels of decision-making. It is developed by nurses for nurses and can assist nurses in practicing ethically and working through ethical challenges that arise in their practice with individuals, families, communities and public health systems.

As regards socio-demographic characteristics of the studied patients with uncontrolled essential hypertension, the findings of the present study showed that two thirds of patients are female. Half of patients their age ranged from 51-65 years. The majority of them were married. The majority of them are illiterate. More than half of them are living in rural. More than half of them are not working. The majority of them are non-smokers. This finding disagrees with Naing et al., (2010), who found that more than half of the patients admitted to hospital for hypertension were 60-69 years.

Regards their sex, two thirds are female. In the same line with Lima et al., (2009) who found in his study that the hypertension in females was slightly more than in males. The present study disagree with Mostafa, (2007) who studied hypertensive patients in outpatient clinic at Sohag University Hospital and reported that, females were less likely than males to have hypertension. The present studies disagree with Roger et al., (2012) found that, uncontrolled hypertension was seen more frequently in males and people with less contact with physicians.

Concerning the place of residence, results revealed that more than two thirds of them were living in the rural areas. This finding is nearly similar to the results of Mustafa, (2007) who stated that about three quarters of their studied sample lived in rural areas. On the other hand, the present study disagree with Arslantas et al., (2008) who reported that the prevalence of hypertension is higher in urban than rural areas.

Concerning their educational level, it was observed that illiteracy have the highest percentage in present studied sample, while little of them can read and write. The current results are similar to Mustafa, (2007) who reported that, the majority of the studied samples were illiterate. On the other hand, the present study disagree with Mahmoud, (2007) who studied the prevalence of hypertension among people more than 35 years old in Sohag city and reported that, more than half of the studied sample were educated. This can be interpreted as the difference between the studies might be due to the differences in study populations.

Concerning their marital status, about two thirds of them were married. This finding is nearly similar to the results of Jesus et al., (2008) who found in his study that, more than half of the studied samples were married. This finding disagreed with Kaplan, (2010) who reported that, the association of marital status with hypertension seems to vary between men and women: never married men have the highest risk 
among men; never married women have the lowest risk. When the sexes are analyzed together widowed individuals have a greater risk of having hypertension. With respect to control, being unmarried is a risk factor.

As regard Family history of hypertension; more than half of patient had a family history of hypertension the present study agreed with Kaplan, (2010) who mentioned that, Primary hypertension is thought to be hereditary because it clusters around families There are inconsistent findings with maternal or paternal linkage but a strong family history of hypertension is observed with most patients with the disease. More than half of patients had no (family history of obesity $\&$ cardiovascular disease. This finding was disagreed by Smeltzer \& Bare, (2003) who reported that, Positive family history of obesity results in an increase probability of hypertension increase of body mass index (BMI), which occur in obesity, it's associated with hypertension the loss of weight is very important factors in the control of hypertension. The Vast majority of patients had increase of symptoms with stress and increase in salt intake. These result agreed with Gallassi et al., (2007) reported that, stress is believed to be a risk factor for hypertension through the mechanism of the sympathetic nervous system. Persistent stress leads to the release of certain hormones notably adrenaline and cortisol resulting in a sustained elevation of blood pressure. Ettner et al., (2011).who mentioned that, Too much salt (sodium) in diet can cause retain fluid to the body, which increases blood pressure.

As regarded assessment of patients' systematic review the present study found that the vast majority of patients were having Tinnitus and vast majority of patients were having headache, dizziness, difficulty breathing and fatigue. This study finding was supported by Coolsby \& Grubbs, (2006) who reported that the more common clinical manifestations of hypertension are headache, tinnitus, dizziness, difficulty breathing and fatigue. Katakamet al., (2008) stated that, assessment of patient's need for care and treatment is an important part of the care process. Planning, implementation and outcome assessment of the care process are based on needs assessment data.

\section{Conclusion \& Recommendations. Conclusions}

- Based on the result of the present study, it can be concluded that:

- Patients who had uncontrolled essential hypertension are at high risk for all clinical manifestations of atherosclerosis It is an independent predisposing factor for heart failure, coronary artery disease, stroke, renal disease, and peripheral arterial disease It is the most important risk factor for cardiovascular morbidity and mortality mentioned in the literature and need standard care to prevent/ reduce these complications.

- Attending training or orientation programs about nursing care standards for patients who had uncontrolled essential hypertension is absolutely lacking for nurses working in the internal medicine department to care for such group of patients.

- Nurses` knowledge and practice regarding patients who had uncontrolled essential hypertension in internal medicine department at Assiut University Hospital are inadequate.

- Application of the developed nursing care standards for patients who had uncontrolled essential hypertension shows a significant improvement in nurses' knowledge and practice. Improving nurses' knowledge and practice have a favourable effect in preventing or reducing hypertension complications.

The study recommended that

Based on the findings of the present study the following recommendations are suggested

\section{For nurses}

1. Continues nursing education and in service training programs at internal medicine department should be organized at Assiut University Hospital and equipped with the necessary educational facilities and materials necessary to upgrade the knowledge and skills of practicing nurses, which will be reflected on better outcome for patients.

2. Nurses should be aware by instructions that given to patients before discharge and inform patients about them.

\section{References}

1. Abd El-Fatah, S., (2013): Assessment of Quality of Life and Nurses' Knowledge for Hypertensive Elderly Patients at Sohag University Hospital. MSc Thesis, Assiut University.Pp.98.

2. Ahmed, G., (2011): Effect of designed nursing protocol on nurses's knowledge and practice regarding haemodialysis patients in the kidney dialysis unit at Assiut University Hospital .MSc Thesis. Faculty of Nursing. Assiut University. Pp 89.

3. American Heart Association, (2012): Heart Disease and Stroke Statistics. Retrieved from: http://www.americanheart.org/presenter.jhtm

4. Arslantas, D., Ayranci, U., Unsal, A., \& Tozun, M., (2008): Prevalence of hypertension among individuals aged 50 years and over and its 
impact on health related quality of life in a semirural area of western Turkey. Chinese Medical Journal. 121 (16): 1524-1531.

5. Calhoun, D.A., Jones, D., Textor, S., Goff, D.C., Murphy, T.P, Toto, R.D et al (2008): Resistant hypertension: diagnosis, evaluation, and treatment: a scientific statement from the American Heart Association Professional Education Committee of the Council for High Blood Pressure Research. Circulation.117 (25): 510-526.

6. Chobanian, A., Bakris, G., Black, H., Cushman, W., Green, L., Izzo, J., \& Wright, J., (2003): The Seventh Report of the Joint National Committee on Prevention, Detection, Evaluation, and Treatment of High Blood Pressure (Complete Report No 04-5230). Bethesda, MD: NHLBI Health Information Center.

7. College of Nurses of Ontario (2009): Professional Standards, Pub. Retrieved from: http://www.cno.org/Global/docs/prac/41006

_ProfStds. pdf.

8. Coolsby, M., \& Grubbs, 1., (2006): Cardiac and Peripheral Vascular Systems, $4^{\text {th }}$. Advanced Assessment to interpreting findings and formulating differential Diagnosis. F. A. Davis Company. Pp 139-140.

9. Douketis, J., Paradis, G., Keller, H., \& Martineau, C., (2005): Canadian guidelines for bodyweight classification in adults: Application in clinical practice to screen for overweight and obesity and to assess disease risk. Canadian Medical Association Journal. 172 (8): 995-998.

10. Ettner, R., Ettner, F., \& White, B., (2011): Secrecy and the Pathogenesis of Hypertension. International Journal of Family Medicine. 45 (4): 3 .

11. Fortunato, N (2002): operating room technique.11 editions, St Louis: Mosby. Pp 206228.

12. Funk, M., Winkler, C., Fashjian, M., Fennie, K., Stephens, K., May, J., \& Drew, B., (2009): Assessment of Risk for a Serious Cardiovascular Event American Heart Association.Circulation.120: 481.

13. Gallassi, R., Morreale, A., \& Pagni, P., (2001): The Relationship between Depression and Cognition, Archives of Gerontology and Geriatrics 2001. 33 (1): 163-71.

14. Ibrahim, M., (2004): Guidelines for Management of Hypertension in Egypt and Developing Countries. Retrieved from: www.ehs-egypt.net/pdf/cor-art-dis.pdfn

15. Isioma, O., (2012): Nurses knowledge and attitude in the prevention and management of high blood pressure in primary health care centers in Delta state Nigeria, Global Advanced Research Journals of Nursing and Midwifery. 1(1): 4-10.

16. Jesus, E., Augusto, M., Gusmão, J., Júnior, D., Ortega, K., \& Pierin A., (2008): Profile of hypertensive patients: biosocial characteristics, knowledge, and treatment compliance, Acta Paul Enferm, 21(1):59-65.

17. Kaplan, N., (2010): Pre hypertension and borderline hypertension. Retrieved from: http://www.uptodate.com/index.

18. Katakam, R., Brukamp, K., \& Townsend, R., (2008): What is the proper workup of a patient with hypertension. Clevel and Clinic Journal of Medicine. 75( 9): 663-673.

19. Keller, K., \& Raines, D., (2005): Arrhythmia knowledge: A qualitative study. Heart and Lung: The Journal of Acute and Critical Care. 34 (5): 113.

20. Lima, M., Barros, M., César, C., Goldbaum, M., Carandina, L., \& Ciconelli, R., (2009): Impact of chronic disease on quality of life among the elderly in the state of São Paulo, Brazil: a population-based study. Rev Panam Salud Publica, Public Health, 25(4): 314-21.

21. Mahmoud, E., (2007): prevalence of hypertension among people more than 35 years old in Sohag city, Risk factors for hypertension. Faculty of Medicine. Inter-medicine Department. Sohag University P31-33. Mangum, S., \& Gruendemann, B., (2001): infection prevention in surgical settings. Ch.2.WB Saunders company .Pp. 181-217.

22. Marquis B., \& Huston C., (2009): Leader ship roles \& management functions in nursing. Ch 13.6th ed., Hong Kong: Lippincott Williams \&Wilkins Company. Pp 371,376.

23. McMahon, D., (2011): Nursing standards of practice, Retrieved from: http://www.hgexperts.com/article.asp?id=6237

24. Mohammed, M., (2010): knowledge, practices and attitude of nurse's toward universal precaution in outpatient clinics Assiut University Hospital, thesis of master degree in Community health nursing, Assuit University. pp.112.

25. Mostafa, M., (2007): Study of hypertensive patient in outpatient clinics. MSc Thesis, Faculty of medicine- internal medicine Department. Sohag university hospital P 4-67.

26. Mostafa, N., (2012): Develop standards of postoperative interventions for lower limb amputation. MSc Thesis, faculty of Nursing. Assiut University.

27. Naing, M., Nanthamongkolchai, S., \& Munsawaengsub, C., (2010): Quality of Life of 
the Elderly People in Einme Township Irrawaddy Division, Myanmar, Asia Journal of Public Health. 1 (2):4-10

28. National Research Council (2012): A Framework for K-12 Science Education: Practices, Crosscutting Concepts, and Core Ideas: The National Academies Press ,p.297. Retrieved from: www.nationalacademies .org.

29. Pickering, T., Hall, J., \& Appel, L., (2005): Astatement for professionals from the subcommittee of professional and Puplic Education of the American Heart Association Council on High Blood pressure Research .Hypertension. 45 (1): 1442-161.

30. Roger, V., Go, A., Lloyd-Jones, D., Benjamin, E., Berry, J., Borden, W., \& Turner, M., (2012): Heart Disease and Stroke Statistics 2012 Update: A Report from the American Heart Association. Circulation. 125(1): e2-e220.

31. Rose Lawence. (2010): American Journal of Nursing, lippincott willams and wilkins, volume 110-issue 5-P 11

32. Samer, A., (2005):Development of Critical Nursing Care Standards for Adult Surgical Patient Pp. (87).

33. Smeltzer, S., \& Bare, B., (2003): Textbook of Medical Surgical Nursing, Assessment and Management of patients with Hypertension. $10^{\mathrm{Th}}$ ed. Lippincott Williams \& Wilkins. Pp 855-865.

34. Suzanne C., Smeltzer, Brenda G., Bare, Janicel. Hinkle, Kerry H., Cheever, (2008): Text book of Medical-Surgical Nursing, lippincott Williams Wilkins, chapter69,1 $11^{\text {th }}$ ed,pp $(2460,2468)$

35. Zipes, D., \& Bonow R., (2005): Heart disease: A textbook of cardiovascular medicine. $7^{\text {th }}$ ed. Philadelphia: saunders. Pp. 657-60.

36. 